\title{
MECHANICAL PROPERTIES OF GEOPOLYMER FILLED WITH FROM COKE PRODUCTION
}

\author{
${ }^{1}$ Iva DUFKOVÁ, ${ }^{2}$ Vladimír KOVAČIČ, ${ }^{3}$ Pavel KEJZLAR \\ ${ }^{1} T U L$ - Technical University of Liberec, Czech Republic, EU, iva.dufkova@tul.cz \\ ${ }^{2}$ TUL - Technical University of Liberec, Czech Republic, EU, vladimir.kovacic@tul.cz, \\ ${ }^{3} T U L$ - Technical University of Liberec, Czech Republic, EU, pavel.kejzlar@tul.cz
}

https://doi.org/10.37904/nanocon.2019.8786

\begin{abstract}
The article deals with the mechanical properties of geopolymers, which were filled micro-and nanoparticles from coke production. As a matrix for the preparation of geopolymer was used materiál Baucis Lk and LNa, commercial product from České lupkové závody Nové Strašecí. It has been chosen a shortened technology using higher temperatures during maturing of the geopolymeru. The influence of particle content on the mechanical properties of the above-mentioned geopolymers is discussed.
\end{abstract}

Keywords: Geopolymer, coke, baucis

\section{INTRODUCTION}

Geopolymers are alkali-activated aluminosilicates. It is a material that can be used in various areas for its ability to exhibit high strength and especially heat resistance. This material is suitable for the production of insulations, especially thermal, concrete repair, processing of different waste and for the fixation of heavy metals and radioactive waste. Similar to cement, them properties depend on the type, size and shape of the filler. Therefore, it is a composite where the geopolymer is a matrix and the filler have a reinforcement function. Geopolymer material, an alkali-activated aluminosilicate, it can be prepared from waste source, such as blast furnace slag or coal-fired fly ash. Geopolymers (aluminosilicates) have the general formula"

$$
\text { (Na, K n \{-(Si-O) z-Al-O\} n. W H } 2 \text { O) (1) }
$$

and chemical reaction is described as polycondensation, i.e. a water release reaction. Alkali in the service of geosilicates representing water glass, $\mathrm{NaOH}$, resp. $\mathrm{KOH}$. it is necessary to emphasize the silicate module, i.e. the $\mathrm{Si} / \mathrm{Al}$ ratio. Chemical reactions are extensively described in publications, e.g. [1], [2], [3]

\section{GEOPOLYMERS}

The commercial geopolymer Baucis Lk was used. A shortened technology of geopolymer maturation was used for sample production:

a) Mixing of cement (powder) with filler for approx. 1 min.

b) An activator was added to the stirred mixture and stirring was continued for about 15 minutes until a gel was formed.

c) The mixture was free of air bubbles by shaking (it is necessary to stir carefully during shaking, otherwise the filler is shaken to the bottom)

d) The mixture was poured into form and covered with foil.

e) The samples were left in the covered form for 3 days, then placed in the covered forms in the oven at $45^{\circ} \mathrm{C}$ for 5 hours.

f) Then the samples were uncovered and left in the oven at $82{ }^{\circ} \mathrm{C}$ for 15 hours. 
The results correspond to a statistical confidence of $96 \%$ of the results obtained on samples produced by the classical method. Samples were created for bending strengths tests of $40 \times 40 \times 160 \mathrm{~mm}$. Bending and compressive strength tests were done on them.

The tests were carried out in accordance with ČSN EN 1015-11 Determination of flexural and compressive strength of hardened mortars. Compressive strength was measured at the ends of broken specimens of bending strength on which were attached steel plates $40 \times 40 \times 5 \mathrm{~mm}$. On Table 1 we can see used mixtures of individual samples

Table 1 Mixture used for produce of geopolymer samples

\begin{tabular}{|c|c|c|c|}
\hline Mixture / Average Wt $[\mathbf{k g}]$ & K1 & K2 & K3 \\
\hline Cement & 1 & 1 & 1 \\
\hline Activator & 0,9 & 0,9 & 0,9 \\
\hline Coke dust & 0 & 0,06 & 0,06 \\
\hline Sand & & & 1 \\
\hline Al & & & 0,016 \\
\hline Note & Compact & Compact & Foamed \\
\hline
\end{tabular}

\section{DUST FROM COKE PRODUCTION}

Coke is generated during the manufacture by pyrolysis of black coal at high temperatures - above $1000{ }^{\circ} \mathrm{C}$ in which the air is excluded. For the production of coke, black coal is used, If possibly with low content of sulfur and suitable properties for thermic treatment. The by-products of the coke production process are: ammonia, crude tar, crude benzol, coke oven gas and sulfur. Due to its porosity, coke is an extremely good thermal insulator. [4]

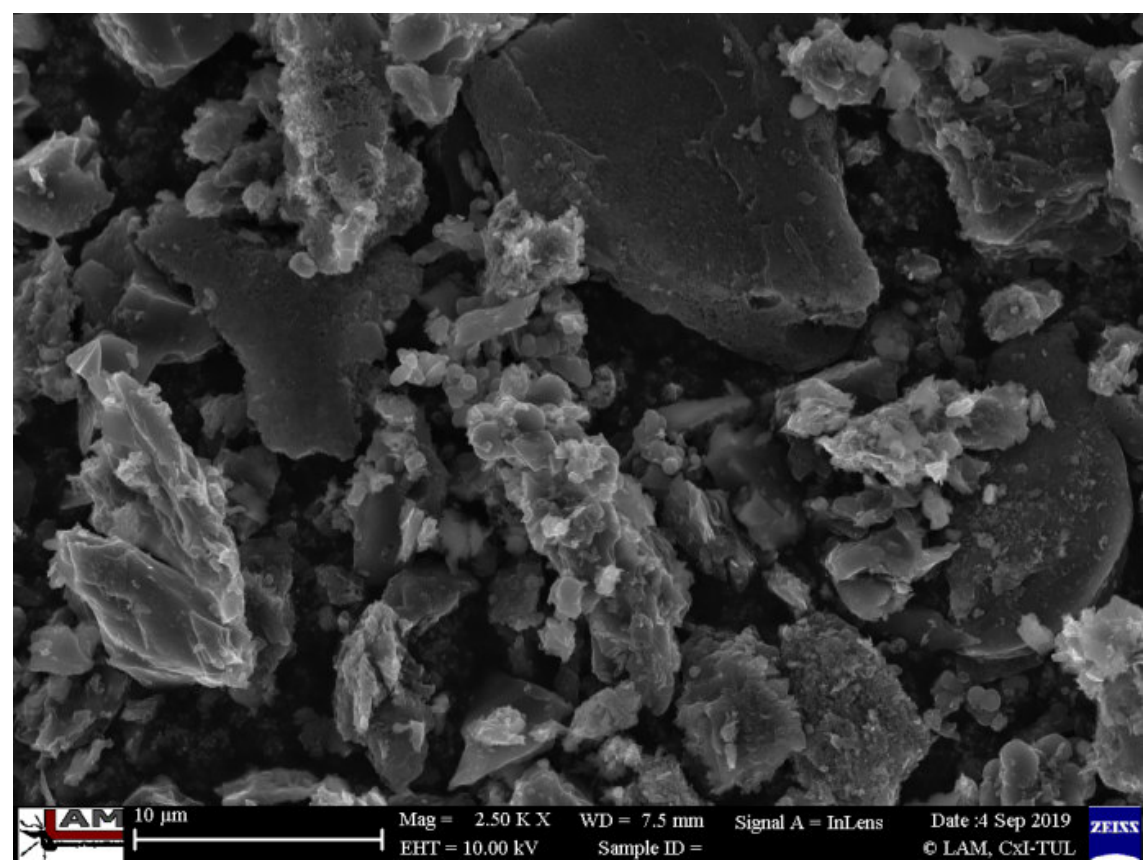

Figure 1 Mixture of micro and nanoparticles in coke dust

For experimental purposes was provide coke dust from coal manufacture in Poland. Particle size analysis and chemical analysis were performed. The analyses were performed on SEM, scanning electron microscope, 
which it uses for imaging a moving electron beam. On Figure 1 we can see a mixture of micro and nanoparticles of coke dust. On Figure 2 there are nicely seen nanoparticles of coke dust. At the same time, the chemical analysis of the particles, as shown in Figure $\mathbf{3}$ and described in Table 2, was performed on the SEM. The result of the measurement showed that the highest amount of chemical elements in coke dust reports carbon in an amount of $76.86 \%$. Other elements, such as oxygen, iron and calcium, already have a much lower proportion and have a value between $4.7-7.4 \%$.

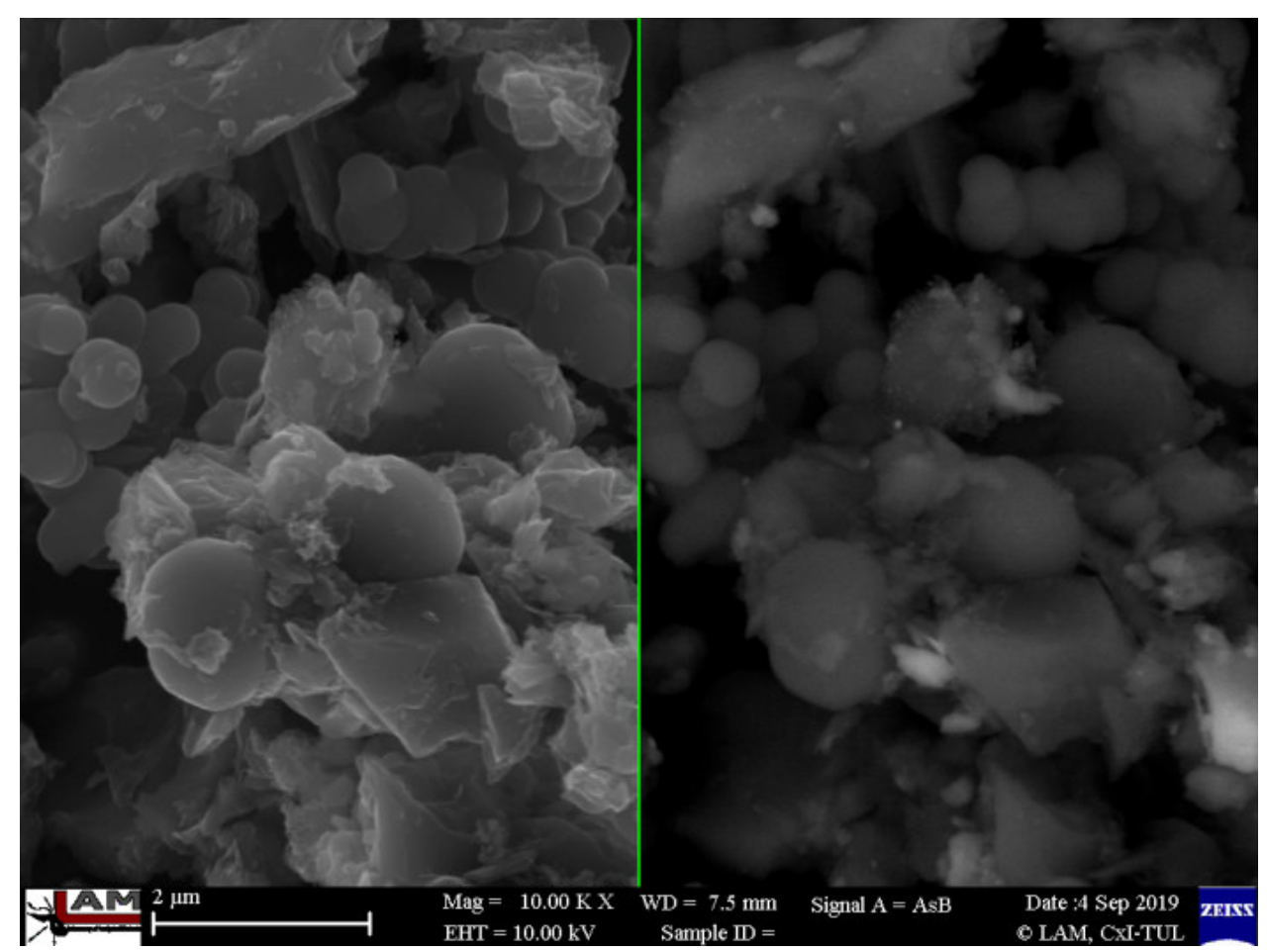

Figure 2 There are nicely seen nanoparticles of coke dust

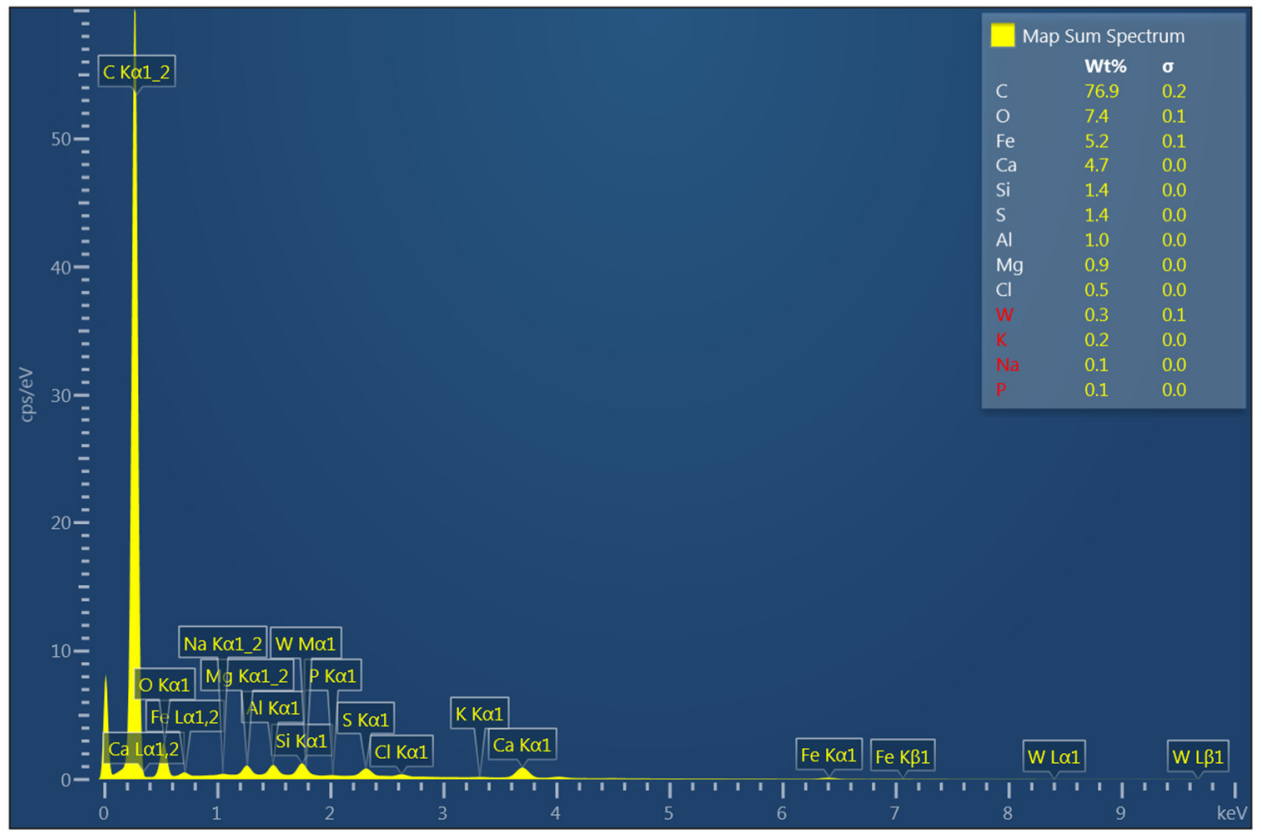

Figure 3 The chemical analysy of the particles of coke dust 
Table 2 Results of chemical analysis of coke dust

\begin{tabular}{|c|c|c|c|c|c|c|c|c|c|c|c|c|c|c|}
\hline Element & $\mathrm{C}$ & $\mathrm{O}$ & $\mathrm{Na}$ & $\mathrm{Mg}$ & $\mathrm{Al}$ & $\mathrm{Si}$ & $\mathrm{P}$ & $\mathrm{S}$ & $\mathrm{Cl}$ & $\mathrm{K}$ & $\mathrm{Ca}$ & $\mathrm{Fe}$ & $\mathrm{W}$ & Total \\
\hline $\begin{array}{c}\text { Average } \\
\mathbf{W t} \%\end{array}$ & 76,89 & 7,41 & 0,11 & 0,88 & 1,02 & 1,02 & 0,10 & 1,35 & 0,53 & 0,16 & 0,05 & 5,16 & 0,25 & 100 \\
\hline
\end{tabular}

\section{EXPERIMENTAL PART}

After the samples were made and cured, the compressive and flexural strength measurements were carried out on the universal strenght testing machine P 100 - Lab Test II. Samples for testing three-point bending strength had dimensions of $40 \times 40 \times 160 \mathrm{~mm}$. For the compressive strength test were used broken parts from previous of test bending.

Steel reinforcement $40 \times 40 \times 3 \mathrm{~mm}$, according to EN 196-1 and EN 1015-11 were used for the test. Determination of bending and compressive strength of hardened mortars [5]. In this case, the loading of the samples corresponds to a $40 \times 40 \times 40 \mathrm{~mm}$ cube. The arrangement of the flexural strength experiment is shown in Figure 4. In Table 3 and Figure 5, we can see the result of meassurement.

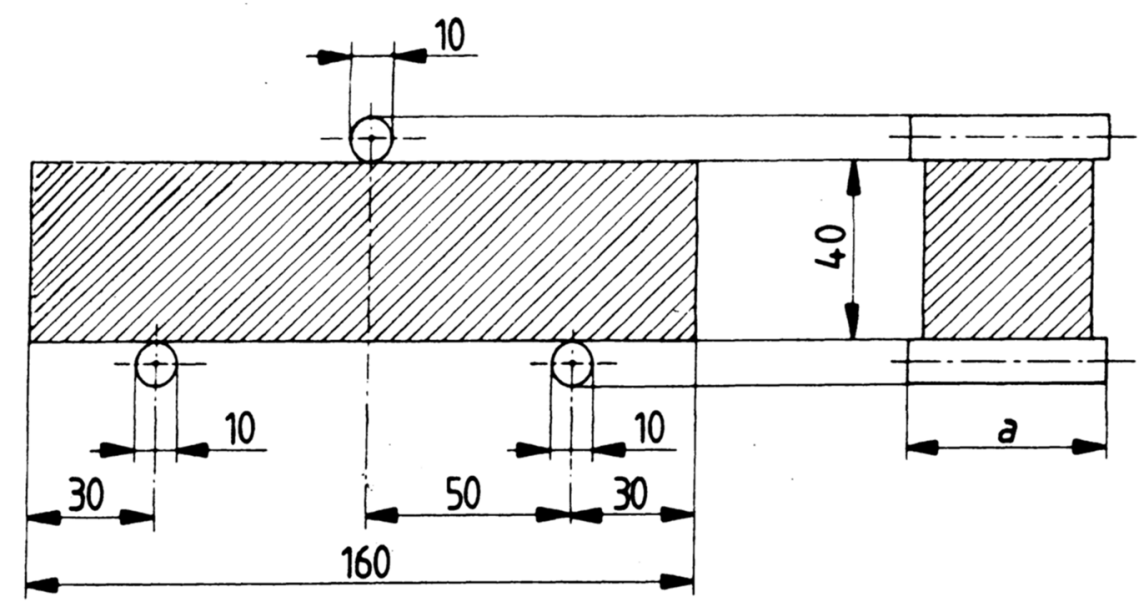

Figure 4 Arrangement of bending and compression tests [2]

The order of magnitude difference between bending and compressive strength was assumed. Geopolymers with coke dust are developed mainly as materials with defined thermal conductivity and this work was focused on verification of their mechanical properties.

Table 3

\begin{tabular}{|c|c|c|}
\hline Sample & Bending strenght [MPa] & Compressive strenght [Mpa] \\
\hline K1 & 57,54 & 731,88 \\
\hline K2 & 55,08 & 660,88 \\
\hline K3 & 1,43 & 68,59 \\
\hline
\end{tabular}

It can be seen from Table 3 and the graph of Figure $\mathbf{5}$ that the addition of coke dust, we can say carbon (see Table 2), slightly reduces the strength of the geopolymer. However, this reduction is in the area of statistical certainty and more measurements on individual samples would be required. 


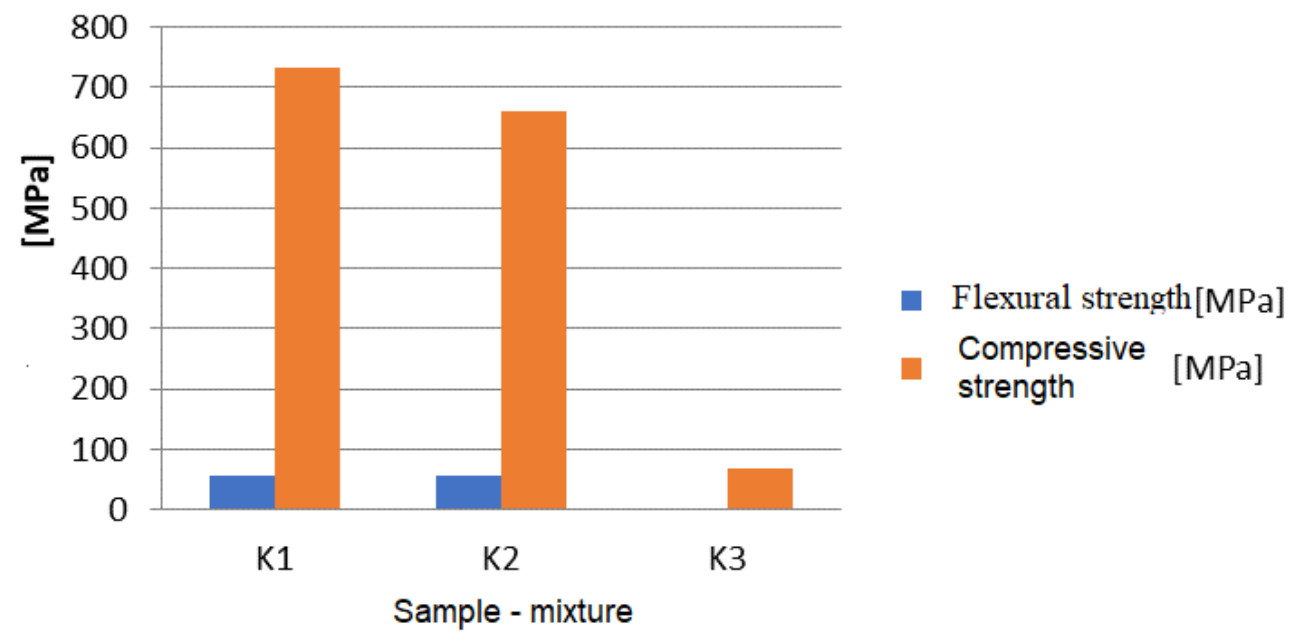

Figure 5 Flexural and compressive strenght

\section{CONCLUSION}

The mechanical properties of carbon-containing geopolymer were investigated. Their use is focused on materials with defined thermal conductivity. Microscopic analysis shows that coke dust contains micro sludge as well as nanoparticles. From the chemical analysis it follows that coke dust can be used for further processing in industry. There is more than $75 \%$ carbon in coke dust. From the flexural and compressive strength values it can be concluded that the low content of coke dust is not relevant in compact geopolymers and the strength values are the same within statistical certainty.

\section{ACKNOWLEDGEMENTS}

The results of the project „Application of geopolymer composites as fire, AGK“, registration number VI20172019055, were obtained through the financial support of the Ministry of interior in the program "The Safety Research of the Czech Republic" 2015-2020 (BV III/1-VS)

\section{REFERENCES}

[1] DAVIDOVITS, J., Geopolymer chemistry \& application, ed. Second. 2008: Institute Géopolymèr - France.

[2] KHATER, H, M., ^, H.A., GAWAAD el A.,: Characterization of alkali activated geopolymer mortar doped with MWCNT. Construction and Building Materials 2016. vol.102 pp. 329-337

[3] PROMODA BEHERA et al.: Microstructure and mechanical properties of carbon microfiber reinforced geopolymers at elevated temperatures. Construction and Building Materials 2018. vol. 160 pp.733-743

[4] OKK KOKSOVNY, a.s. firemní sdělení. Available from http://info-lit.shrivenham.cranfield.ac.uk/index.html. [viewed 2019-09-30].

[5] ČSN EN 1015-11 Stanovení pevnosti ztvrdlých malt v tahu za ohybu a v tlaku. 